\title{
A New Decision Model for Reducing Trim Loss and Inventory in the Paper Industry
}

\author{
Fu-Kwun Wang and Feng-Tai Liu \\ Department of Industrial Management, National Taiwan University of Science and Technology, Taipei 106, Taiwan \\ Correspondence should be addressed to Fu-Kwun Wang; fukwun@mail.ntust.edu.tw
}

Received 1 October 2013; Revised 27 November 2013; Accepted 7 December 2013; Published 21 January 2014

Academic Editor: Aderemi O. Adewumi

Copyright ( 2014 F.-K. Wang and F.-T. Liu. This is an open access article distributed under the Creative Commons Attribution License, which permits unrestricted use, distribution, and reproduction in any medium, provided the original work is properly cited.

In the paper industry, numerous studies have explored means of optimizing order allocation and cutting trim loss. However, enterprises may not adopt the resulting solutions because some widths of the inventory exceed or are less than those required for acceptable scheduling. To ensure that the results better suit the actual requirements, we present a new decision model based on the adjustment of scheduling and limitation of inventory quantity to differentiate trim loss and inventory distribution data. Differential analysis is used to reduce data filtering and the information is valuable for decision making. A numerical example is presented to illustrate the applicability of the proposed method. The results show that our proposed method outperforms the manual method regarding scheduling quantity and trim loss.

\section{Introduction}

Numerous industries with bulk production modes, such as the industrial-use paper industry, have gradually changed their production environments to high-mix low-volume production. Customer requirements for high-mix low-volume production and instant supply also increase the difficulty of optimizing production scheduling. An issue with even greater significance is how to properly employ production scheduling flexibility and coordinated supplementary measures. In this paper, we consider two main issues in relation to the production planning of industrial paper. (1) If production scheduling is fixed, how may the trim loss ratio and production inventory be reduced, whether evenly distributed in different widths of inventory or not. (2) Does increasing or decreasing the production of scheduling produce better results for inventory distribution and trim loss ratio better than the original scheduling? Since the 1960s [1], numerous studies have examined how to configure orders most effectively to optimize production scheduling. However, these optimized results have not been able to satisfy the requirements of numerous managers because, in situations of raw order production, if the structure remains poor after the permutation and combination of orders, significant trim loss can occur. Thus, managers must abandon optimized scheduling and use their experience to identify the best solution.

Most cutting stock problems (CSPs) are classified as NP-complete, meaning that it is difficult to obtain optimal solutions. Gilmore and Gomory [1] presented a delayed pattern generation technique for solving a one-dimensional cutting problem using linear programing. Other methods can also be found in the literature [2-13]. Morabito and Arenales [14] considered different objectives (e.g., cutting time and trim loss) in the preparation of the cutting plan. Menon and Schrage [15] proposed a bound-based approach to solve the problem of allocating orders to machines in the paper industry. Wäscher et al. [16] provided a good review of several efficient heuristic methods utilizing either pattern-oriented or item-oriented approaches. Matsumoto et al. [17] proposed a generalization of the cutting pattern called the cutting group in a paper tube factory. Mobasher and Ekici [18] developed two local search algorithms and a column generation based heuristic algorithm to solve the cutting stock problem with setup cost.

In the overall order optimization process, not every cutting configuration meets the needs of the manager because some cutting configurations produce greater trim losses. Generally, managers assign the inventory quantity according 
to the size of the trim loss and then search for another optimized solution. Therefore, appropriate replanning of inventory and orders is undertaken to ensure that it is closer to the producer's requirements. Gramani and França [19] proposed a mathematical model for coupling lot sizing and two-dimensional cutting stock problems. Ritvirool [20] presented an integer linear programming (ILP) model to minimize trim loss in a produce-handling vehicle production plant. Chauhan et al. [21] presented a model to decide the parent roll assortment and assignments to finished products based on these products demand processes, desired service levels, trim loss, and inventory holding costs in a paper mill. Poltroniere et al. [22] presented a mixed linear integer optimization model to couple the production planning and the cutting process in the paper industry.

To prevent the trim loss generated after optimization, Kos and Duhovnik [23] included reusable inventory, which is an extension of the usable leftover solution. The usable leftover material is used in the next cutting plan. Related studies [2428] all propose similar optimal solutions. Erjavec et al. [29] considered trim loss, inventory costs, and shortage costs and developed a model for the solution of the inventory level with the lowest overall cost. Regarding the delivery period, some industries add 1 to 3 days after the paper type is produced as the product delivery period. These additional days are used to increase production flexibility and prevent late deliveries because of transportation factors. This supply chain mode is similar to the process improvements proposed by Erjavec et al. [30].

This study proposes a model based on the adjustment of scheduling and the limitation of inventory quantity to differentiate trim loss ratio and inventory distribution data. We also use the integer programing method to determine the optimal adjustment of order allocation, inventory filtering, and production scheduling. Finally, we use differential analysis to reduce data filtering. This valuable information should enable companies to solve the problems of inventory distribution and the depletion ratio more effectively. The remainder of this paper is organized as follows. In Section 2, the definition of the problem in the paper industry is presented. A decision model is developed in Section 3. In Section 4, an empirical case is employed to calculate and illustrate the proposed model. Finally, conclusions are drawn in Section 5.

\section{Problem Definition}

The production of industrial-use paper begins from raw material to reels and then from reels to rolls as finished goods. The entire operation mode is cyclical production, which is the only method for achieving efficient production. Therefore, the leftover material is not used in a follow-up production cycle. For this scheduling, the customer's paper requirements are obtained and the market demand is predicted. In the combined production-marketing meeting, the number of production days and the production quantity of paper types are determined. $N$ number of reels is considered as the production quantity and st number of rolls can be produced from each reel. Thus, the problem encountered is the optimization of $N$ number of reels for st number of rolls to fulfill customers' orders (see Figure 1).

Regarding production planning, actual supply and demand figures are obtained for scheduling. In order to meet the overall order specifications and reduce trim loss during the production process, the decision-making model proposed by Keskinocak et al. [31] is used to optimize overall production scheduling. However, actual production cannot achieve the optimal result of zero depletion. Indeed, the overall production capacity is typically greater than the order to ensure that the customer's and production requirements are met (see Figure 2). Therefore, decision makers often encounter difficulties in determining the scheduling quantity and production inventory so that they are evenly distributed in different widths. To solve these two issues, decision makers use their experience to adjust the scheduling quantity to meet production requirements. Unfortunately, these solutions are not optimized or efficient. In order to improve the overall production efficiency and reduce the time required for manual calculation, a new decision model is needed to react more flexibly to the market and increase the comprehensiveness of the production structure.

\section{Decision Model for Scheduling}

In order to formulate a decision-making model or a mathematical model, we consider the following notation:

$\mathrm{OW}_{i}=$ an order width, with $i=1, \ldots, m$, and $m$ is the number of order width;

$D_{i}=$ demand for $\mathrm{OW}_{i}$, with $i=1, \ldots, m$, and $m$ is the number of order width;

$\mathrm{IW}_{j}=$ an inventory width, with $j=1, \ldots, n$, and $n$ is the number of inventory width;

$\mathrm{PW}_{k}=$ a production width, with $k=1, \ldots, o$, and $o$ is the number of production width;

$\mathrm{DPW}_{k}=$ demand for $\mathrm{PW}_{k}$, with $k=1, \ldots, o$, and $o$ is the number of production width;

$\mathrm{PPW}_{k s}=$ the pattern for $\mathrm{PW}_{k}$, with $s=1, \ldots, c$, and $c$ is the number of pattern;

$\mathrm{QIL}_{k s}=$ the quantity of inventory limit for $\mathrm{PW}_{k}$, with $s=1, \ldots, c$, and $c$ is the number of pattern;

PSQ = production scheduling quantity;

$T$ = flexible adjustment multiple;

$\mathrm{PSR}=\mathrm{PSQ} * T=$ reels set in production scheduling;

$\mathrm{UB}=$ upper bound for trim loss;

$\mathrm{PSQ}_{f}=$ a production scheduling quantity, with $f=$ $1, \ldots, v$, and $v$ is the number of production scheduling quantity;

$\mathrm{TL}_{f_{s}}=$ postoptimization trim loss ratio;

$\mathrm{NPW}_{f_{s k}}=$ the number of $\mathrm{PW}_{k}$; for nonfulfilled order, with $f=1, \ldots, v$, and $s=1, \ldots, c$; 


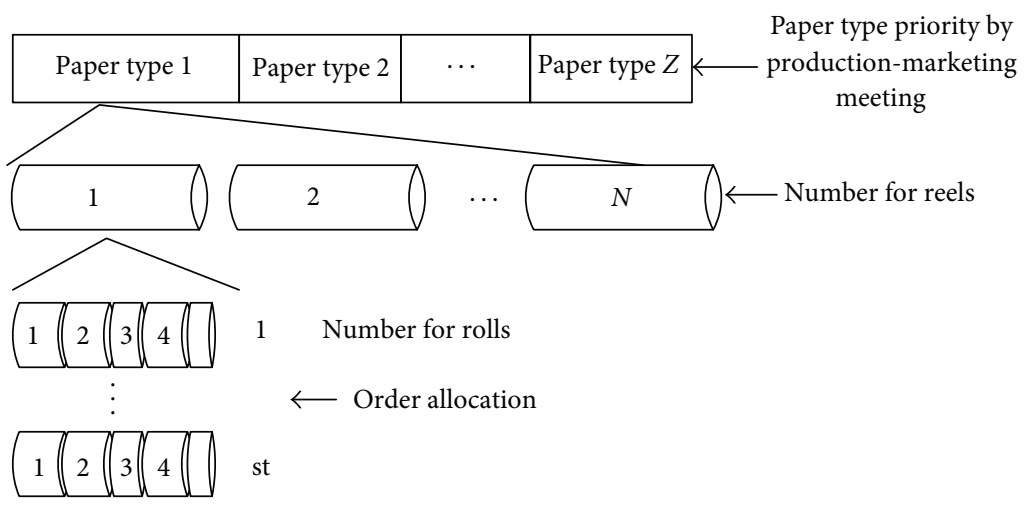

FIgURE 1: Production planning in the paper industry.

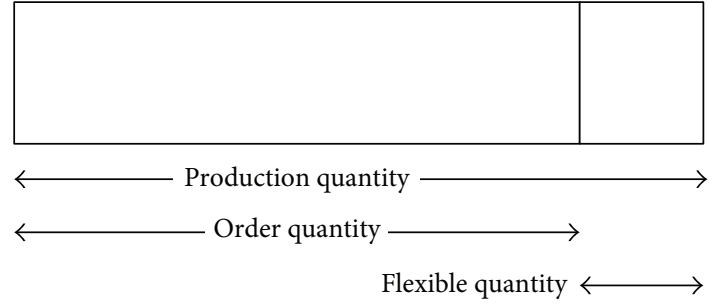

FIgURE 2: Information of order and production.

$\mathrm{SI}_{f s}=\mathrm{TL}_{(f+1) s}-\mathrm{TL}_{f s}=$ difference of trim loss ratio of the scheduled quantities for each item of inventory limit, with $f=1, \ldots, v$, and $s=1, \ldots, c$;

$\mathrm{IS}_{f_{s}}=\mathrm{TL}_{f(s-1)}-\mathrm{TLP}_{f_{s}}=$ difference of trim loss ratio of inventory limit for each item of scheduled quantities, with $f=1, \ldots, v$, and $s=1, \ldots, c$.

3.1. Decision Model. To meet customer needs and optimize scheduling quantity, when decision makers analyze production planning, they must consider the trim loss, production volume, and the inventory required to satisfy the practical production requirements. Controlling trim loss, production volume, and inventory is the only strategy to improve production decision making. The decision-making model consists primarily of configuring the production inventory paper width according to the paper width and volume in the order. The minimum production capacity and overall trim loss can be obtained after aggregating the paper width and minimum requirements. If the production capacity, trim loss, and inventory are within a tolerable range for the decision maker, the production scheduling is completed. If the trim loss is excessive or the inventory must be retained, the production capacity must be adjusted and the maximum production capacity must be obtained using the minimum depletion level. The maximum production capacity is used to confirm the quantity of production capacity required to meet the ideal scheduling quantity. This enables the decision makers to obtain the optimized production capacity, trim loss, and inventory configuration between the minimum production volume and the maximum production volume.
In addition, this enables the overall trim loss to be controlled within the decision maker's ideal range, without limitations from a preset allowable trim loss value that would prevent an optimized solution from being identified.

The steps in the overall decision-making model in Figure 3 are as follows.

Step 1. Define the order and inventory paper width and volume. The inventory paper width is the high turnover of inventory paper.

Step 2. Define the limits of inventory paper width and volume for each item. Aggregate the order and inventory paper width and volume to the production paper width and volume and limit the inventory paper quantity to ensure that it correlates with the actual production paper width and volume.

Step 3. Define the maximum tolerable scheduling quantity as a multiple of the production scheduling quantity to maintain a flexible future scheduling quantity and optimize trim loss.

Step 4. Limit the trim loss quantity and obtain the minimum trim loss using the integer programing method. The production quantity for each paper width must be equal to or greater than the quantity required by the customer.

Step 5. Store the optimized scheduling quantity, trim loss ratio, and nonorder (inventory) paper width and volume.

Step 6. Determine whether an optimal solution exists. If so, go to Step 8. If not, go to Step 7.

Step 7. Adjust the scheduling quantity. To reduce this, return to Step 4 .

Step 8. Determine whether the number of items in the inventory limit derived from the solution is greater than the total number of items. If yes, go to Step 10. If not, go to Step 9.

Step 9. Aggregate the production paper width and quantity and adjust the inventory paper width and quantity to the actual production paper width and quantity. Return to Step 3. 


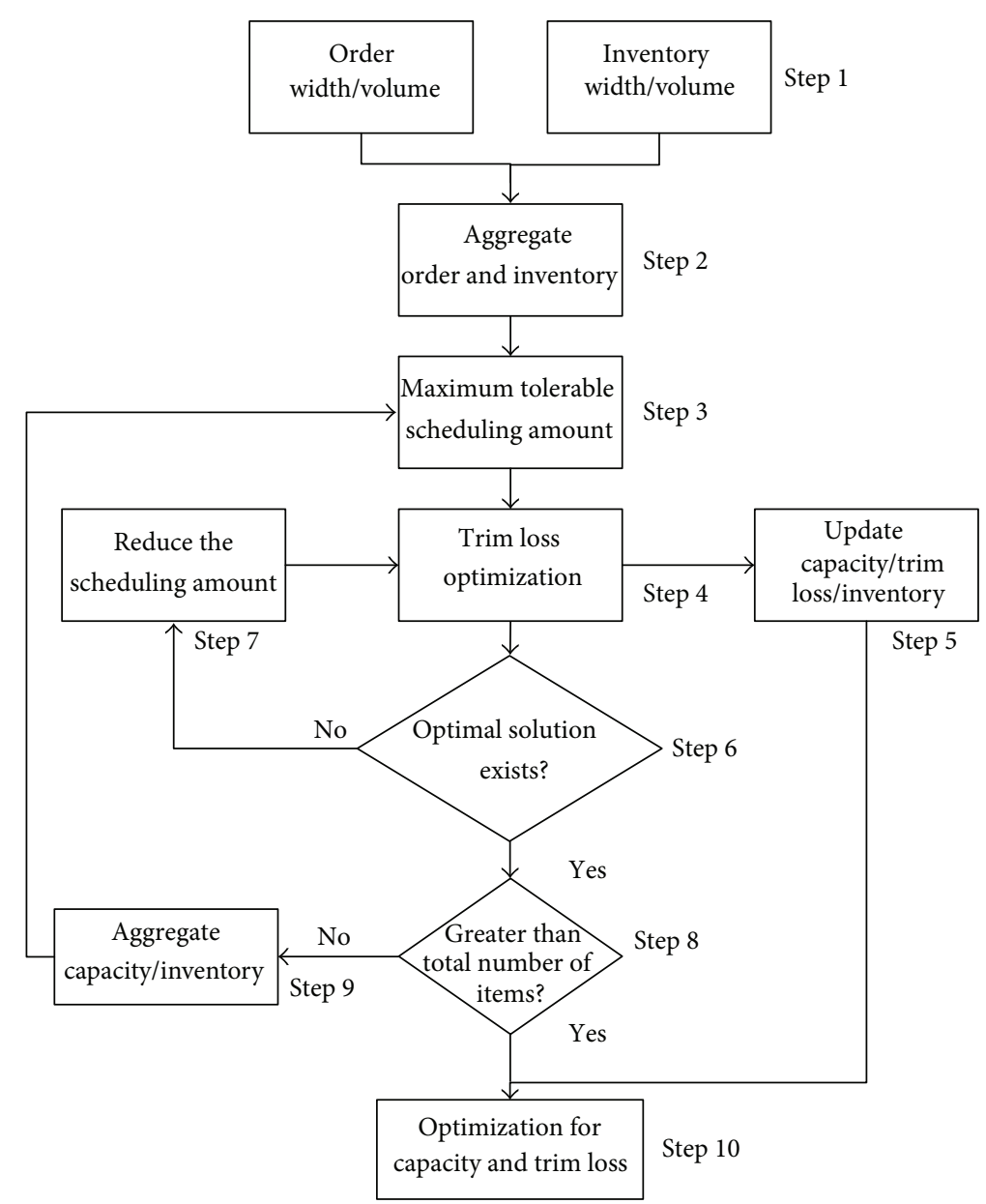

Figure 3: Decision model.

Step 10. Obtain the differential analysis of the trim loss ratio and then optimize the storage-scheduling quantity and trim loss information. Following optimization, the decision makers finally confirm the production scheduling quantity.

In production planning for industrial paper, each reel produces st number of sets, and an st multiple of products is produced by cutting the reels. To allow the production trim loss to be controlled within a certain range and to provide a flexible scheduling quantity, the overall production paper width is aggregated as $\mathrm{IW}_{j}$ and $\mathrm{OW}_{i}$, and the producible paper width $\mathrm{PW}_{k}$ is obtained. Regarding the control of paper width and volume, the produced paper width and volume must meet $D_{i}$. The level of inventory controls the quantity of $\mathrm{QIL}_{k s}$. Here, $D_{i}$ and $\mathrm{QIL}_{k s}$ are aggregated and the producible paper width and quantity $\mathrm{DPW}_{k s}$ are obtained.

The scheduling quantity is adjusted according to how the production decision makers view the trim loss level and the urgency of the order. Therefore, although the PSQ can be optimized, they do not represent the production capacity that is acceptable to the decision makers. Instead, the trim loss and production capacity data are provided to the decision makers who make the final decision. After obtaining the $\mathrm{DPW}_{k s}$ and PSR, the integer programing method is used to optimize trim loss. The postoptimization scheduling quantity and trim loss are then stored in the data table. After the related data are stored, the scheduling quantity is reduced to obtain the next scheduling quantity. Next, optimization is again conducted, and the PSR and trim loss data are again stored. Thus, the scheduling quantity is reduced and optimized repeatedly until optimal or lower than the PSQ. Subsequently, the inventory quantities $\mathrm{QIL}_{k s}$ and $\mathrm{PPW}_{k s}$ are changed and optimization is conducted again until $s$ is greater than $c$, which completes the entire operation. The optimization process is shown in Algorithm 1, where $a_{k j}=$ the number of width $k$ in pattern $j$ and is integer; $x_{j}=$ the number of pattern $j$ and is integer; $L=$ the width of reel; $s t$ $=$ the number of set in reel; Solve $=$ whether optimization is possible; TTL $=$ postoptimization trim loss; $f=$ optimized solution number.

3.2. Decision Making for Scheduling Quantity and Trim Loss. Typically, a larger scheduling quantity produces greater trim loss. Therefore, the scheduling quantity is multiplied to prevent situations in which the scheduling quantity and trim loss cannot be optimized because of a limited scheduling quantity. 


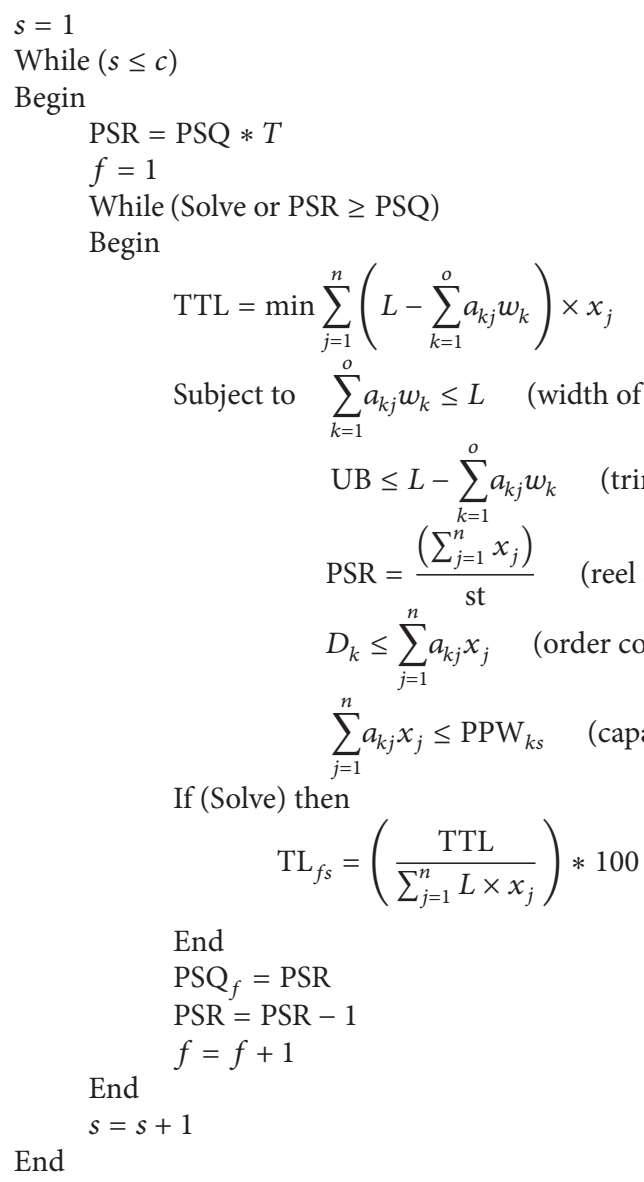

Algorithm 1

Therefore, $\mathrm{PSQ}_{f}$ and $\mathrm{TL}_{f s}$ are entered during the optimization process to increase decision makers' understanding of the influence that increases or decreases in production capacity have on the trim loss level. In this study, a differential analysis of the trim loss was conducted to ensure that the scheduling quantity and trim loss met the decision makers' requirements.

In the $\mathrm{PSQ}_{f}$ and $\mathrm{TL}_{f s}$ table,s was selected as the set value and $f$ was the variable value employed to conduct differential analysis of the trim loss. First, the difference between $\mathrm{TL}_{f s}$ and $\mathrm{TL}_{(f+1) s}$ is entered into $\mathrm{SI}_{f s}$, and the result of $\mathrm{SI}_{f s}$ is used to obtain the mean. When $\mathrm{SI}_{f s}$ is greater than the mean, the maximum value of $f$ is reduced. If $\mathrm{SI}_{(f+1) s}$ cannot be optimized and $\mathrm{SI}_{f s}$ is greater than the mean, plan A of the decision suggestion can be obtained.

Similarly, the difference between $\mathrm{TL}_{f s}$ and $\mathrm{TL}_{(f+1) s}$ is entered into IS $\mathrm{I}_{f(s+1)}$, and the result of $\mathrm{IS}_{f s}$ is used to obtain the mean. When IS $f_{s}$ is greater than the mean, the minimum value of $s$ is summed. If IS $f_{s}$ cannot be optimized and IS $S_{f(s+1)}$ exceeds the mean, plan $\mathrm{B}$ of the decision suggestion can be obtained.

Intersection analysis is conducted on plans $\mathrm{A}$ and $\mathrm{B}$ to obtain the scheduling solution $\mathrm{C}$. The values of $\mathrm{C}$ are organized in sequence from large to small, and the smaller number is subtracted from the larger number. The result of this subtraction is used to obtain the mean, and the items that exceed the mean are filtered out to obtain the optimal decision suggestion. The decision makers can select the desired inventory results according to their requirements and perform a final confirmation of the scheduling and inventory quantity.

\section{Illustrative Example}

In an actual case of industrial paper production, we set the current scheduling quantity as PSQ reels, and each reel can produce stnumber of roll sets. The cutting machine's maximum width limit is $L$ and the maximum trim loss is UB. These parameters are defined as $s t=3, L=4600 \mathrm{~mm}$, $\mathrm{PSQ}=46$, and $\mathrm{UB}=999$.

The application program was implemented to provide the described optimization functionality. As optimization is numerically intensive, the application program was divided into the engine and the user interface. The engine interface was written in Lingo Software [32]. The user interface in Visual Basic 5 enables the navigation of data flow from various input sources from/to a common company database. 
TABLE 1: Product order information and adjusted data for $\mathrm{PW}_{k}$, $\mathrm{QIL}_{k s}$, and $\mathrm{PPW}_{k s}$.

\begin{tabular}{lcccccc}
\hline$k$ & $\mathrm{OW}_{k}(\mathrm{~mm})$ & $\mathrm{IW}_{k}(\mathrm{~mm})$ & $\mathrm{PW}_{k}(\mathrm{~mm})$ & $\mathrm{D}_{k}$ & $\mathrm{QIL}_{k s}$ & $\mathrm{PPW}_{k s}$ \\
\hline 1 & $\mathrm{X}$ & 1000 & 1000 & 0 & $5 / 10 / 15 / 20 / 100$ & $5 / 10 / 15 / 20 / 100$ \\
2 & $\mathrm{X}$ & 1100 & 1100 & 0 & $5 / 10 / 15 / 20 / 100$ & $5 / 10 / 15 / 20 / 100$ \\
3 & 1200 & 1200 & 1200 & 7 & $5 / 10 / 15 / 20 / 100$ & $12 / 17 / 22 / 27 / 107$ \\
4 & 1300 & 1300 & 1300 & 22 & $5 / 10 / 15 / 20 / 100$ & $27 / 32 / 37 / 42 / 122$ \\
5 & $\mathrm{X}$ & 1400 & 1400 & 0 & $5 / 10 / 15 / 20 / 100$ & $5 / 10 / 15 / 20 / 100$ \\
6 & 1500 & 1500 & 1500 & 28 & $5 / 10 / 15 / 20 / 100$ & $33 / 38 / 43 / 48 / 128$ \\
7 & 1600 & 1600 & 1600 & 58 & $5 / 10 / 15 / 20 / 100$ & $63 / 68 / 73 / 78 / 158$ \\
8 & 1700 & 1700 & 1700 & 47 & $5 / 10 / 15 / 20 / 100$ & $52 / 57 / 62 / 67 / 147$ \\
9 & 1800 & 1800 & 1800 & 43 & $5 / 10 / 15 / 20 / 100$ & $48 / 53 / 58 / 63 / 143$ \\
10 & 1900 & 1900 & 1900 & 7 & $5 / 10 / 15 / 20 / 100$ & $12 / 17 / 22 / 27 / 107$ \\
11 & 2000 & 2000 & 2000 & 20 & $5 / 10 / 15 / 20 / 100$ & $25 / 30 / 35 / 40 / 120$ \\
12 & 2100 & 2100 & 2100 & 9 & $5 / 10 / 15 / 20 / 100$ & $14 / 19 / 24 / 29 / 109$ \\
13 & 2200 & 2200 & 2200 & 30 & $5 / 10 / 15 / 20 / 100$ & $35 / 40 / 45 / 50 / 130$ \\
14 & 2300 & 2300 & 2300 & 7 & $5 / 10 / 15 / 20 / 100$ & $12 / 17 / 22 / 27 / 107$ \\
15 & 2400 & 2400 & 2500 & 12 & $5 / 10 / 15 / 20 / 100$ & $17 / 22 / 27 / 32 / 112$ \\
16 & 2500 & 2500 & 20 & $5 / 10 / 15 / 20 / 100$ & $25 / 30 / 35 / 40 / 120$ \\
\hline
\end{tabular}

Note: $\mathrm{X}=$ not available.

TABLE 2: The results of $\mathrm{TL}_{f s}$ under different optimized solution numbers.

\begin{tabular}{ccccccc}
\hline$f$ & PSQ $_{f}$ & 1 & 2 & 3 & 4 & 5 \\
\hline 1 & 52 & $\mathrm{X}$ & $\mathrm{X}$ & 0.08 & 0 & 0 \\
2 & 51 & $\mathrm{X}$ & $\mathrm{X}$ & 0.10 & 0 & 0 \\
3 & 50 & $\mathrm{X}$ & 0.43 & 0.13 & 0.04 & 0 \\
4 & 49 & $\mathrm{X}$ & 0.50 & 0.16 & 0.09 & 0.03 \\
5 & 48 & $\mathrm{X}$ & 0.60 & 0.21 & 0.15 & 0.12 \\
6 & 47 & $\mathrm{X}$ & 0.74 & 0.31 & 0.23 & 0.22 \\
7 & 46 & 3.0 & 0.95 & 0.41 & 0.33 & 0.32 \\
8 & 45 & 3.3 & 1.20 & 0.61 & 0.43 & 0.42 \\
9 & 44 & $\mathrm{X}$ & $\mathrm{X}$ & $\mathrm{X}$ & $\mathrm{X}$ & $\mathrm{X}$ \\
\hline
\end{tabular}

Note: $\mathrm{X}=$ not available.

TABLE 3: The results of differential analysis between $\mathrm{TL}_{f s}$ and $\mathrm{TL}_{(f+1) s}$.

\begin{tabular}{|c|c|c|c|c|c|c|}
\hline \multirow{2}{*}{$f$} & \multirow{2}{*}{$\mathrm{PSQ}_{f}$} & \multicolumn{5}{|c|}{$s$} \\
\hline & & 1 & 2 & 3 & 4 & 5 \\
\hline 1 & 52 & & & 0.02 & 0 & 0 \\
\hline 2 & 51 & & & 0.03 & 0.04 & 0 \\
\hline 3 & 50 & & 0.07 & 0.03 & 0.05 & 0.03 \\
\hline 4 & 49 & & 0.10 & 0.05 & 0.06 & 0.09 \\
\hline 5 & 48 & & 0.14 & 0.10 & 0.08 & 0.10 \\
\hline 6 & 47 & & 0.21 & 0.10 & 0.10 & 0.10 \\
\hline 7 & 46 & 0.3 & 0.25 & 0.20 & 0.10 & 0.10 \\
\hline 8 & 45 & & & & & \\
\hline 9 & 44 & & & & & \\
\hline & ge value & 0.3 & 0.15 & 0.08 & 0.06 & 0.06 \\
\hline
\end{tabular}

According to the decision model and the optimization process described in Section 3, the details are as follows.

Step 1. Collect $\mathrm{OW}_{i}, \mathrm{IW}_{j}$, and $D i$, where $i=1,2, \ldots, 12$ and $j=1,2, \ldots, 15$.

Step 2. Aggregate $\mathrm{OW}_{i}$ and $\mathrm{IW}_{j}$ to $\mathrm{PW}_{k}$, define the limitation quantity $\mathrm{QIL}_{k s}$, and aggregate $D i$ and $\mathrm{QIL}_{k s}$ to $\mathrm{PPW}_{k s}$, where $k=1,2, \ldots, 16$ and $s=1,2, \ldots, 5$ (see Table 1 ).

Step 3. Define the parameter $T=1.15$ and PSR $=\mathrm{PSQ} * T$ to obtain PSR $=52$.

Step 4. Obtain the minimum trim loss using the integer programing method.

Step 5. Store the optimized scheduling quantity $\mathrm{PSQ}_{f}$, depletion ratio $\mathrm{TL}_{f s}$, and nonorder (inventory) paper width and quantity $\mathrm{NPW}_{f s k}$.

Step 6. Determine whether an optimal solution exists or not. If yes, go to Step 8. If no, go to Step 7.

Step 7. Adjust the scheduling quantity PSR.

Step 8. Determine whether the number of items in the inventory limit derived from the solution is greater than the total number of items. If yes, go to Step 10. If not, go to Step 9.

Step 9. Obtain the next $\mathrm{QIL}_{k s}$ and aggregate $D i$ to $\mathrm{PPW}_{k s}$; then go to Step 3.

Step 10. Obtain $\mathrm{PSQ}_{f}$ and $\mathrm{TL}_{f s}$ (see Table 2).

Conducting differential analysis of the trim loss, the difference between $\mathrm{TL}_{s}$ and $\mathrm{TL}_{(f+1) s}$ is entered into $\mathrm{SI}_{f s}$, and 
TABLE 4: The results of differential analysis between $\mathrm{TL}_{f_{s}}$ and $\mathrm{TL}_{f(s+1)}$.

\begin{tabular}{|c|c|c|c|c|c|c|c|}
\hline \multirow{2}{*}{$f$} & \multirow{2}{*}{$\mathrm{PSQ}_{f}$} & \multicolumn{5}{|c|}{$s$} & \multirow{2}{*}{ Average value } \\
\hline & & 1 & 2 & 3 & 4 & 5 & \\
\hline 1 & 52 & & & & 0.08 & 0 & 0.04 \\
\hline 2 & 51 & & & & 0.10 & 0 & 0.05 \\
\hline 3 & 50 & & & 0.30 & 0.09 & 0.04 & 0.14 \\
\hline 4 & 49 & & & 0.34 & 0.07 & 0.06 & 0.16 \\
\hline 5 & 48 & & & 0.39 & 0.06 & 0.03 & 0.16 \\
\hline 6 & 47 & & & 0.43 & 0.08 & 0.01 & 0.17 \\
\hline 7 & 46 & & 2.05 & 0.54 & 0.08 & 0.01 & 0.67 \\
\hline 8 & 45 & & 2.10 & 0.59 & 0.18 & 0.01 & 0.72 \\
\hline 9 & 44 & & & & & & \\
\hline
\end{tabular}

TABLE 5: The comparison results of $\mathrm{TL}_{f s}(\%)$ for different scenarios.

\begin{tabular}{lcccccccc}
\hline$s$ & 1 & 1 & 2 & 2 & 2 & 3 & 3 & Differential \\
PSQ & 45 & 46 & 45 & 46 & 47 & 47 & 48 & mean \\
\hline Trim loss (\%) & 3.3 & 3.0 & 1.2 & 0.95 & 0.74 & 0.31 & 0.21 & \\
Deviation & & 0.3 & 1.8 & 0.25 & 0.21 & 0.43 & 0.10 & 0.52 \\
\hline
\end{tabular}

the mean is obtained from the result of $\mathrm{SI}_{f s}$. When $\mathrm{SI}_{f s}$ is greater than the mean, $\left\{\mathrm{SI}_{44}, \mathrm{SI}_{45}, \mathrm{SI}_{53}, \mathrm{SI}_{54}, \mathrm{SI}_{55}, \mathrm{SI}_{62}, \mathrm{SI}_{63}\right.$, $\left.\mathrm{SI}_{64}, \mathrm{SI}_{65}, \mathrm{Sdec}_{71}, \mathrm{SI}_{72}, \mathrm{SI}_{73}, \mathrm{SI}_{74}, \mathrm{SI}_{75}\right\}$ is obtained. If $\mathrm{SI}_{(f+1) s}$ cannot be optimized and $\mathrm{SI}_{f s}$ is greater than the mean, the decision suggestion plan can be obtained (see Table 3). That is, we have $\left\{\mathrm{SI}_{81}, \mathrm{SI}_{82}, \mathrm{SI}_{83}, \mathrm{SI}_{84}, \mathrm{SI}_{85}\right\}$.

With $s=2$ as the paradigm, $\mathrm{SI}_{82}=\mathrm{TL}_{92}-\mathrm{TL}_{82}$ and is consistently calculated as $\mathrm{SI}_{12}=\mathrm{TL}_{22}-\mathrm{TL}_{12}$. If $\mathrm{TL}_{f s}$ cannot be optimized, such as in $\mathrm{TL}_{22}$, the calculation is ignored. In this case, the differential mean of 0.15 is obtained and $\mathrm{SI}_{72}$ and $\mathrm{SI}_{62}$ are greater than the mean. However, $\mathrm{SI}_{82}$ cannot be optimized and $\mathrm{SI}_{72}$, is greater than the mean; thus, $\mathrm{SI}_{82}$ must be included for consideration.

Similarly, the difference between $\mathrm{TL}_{f s}$ and $\mathrm{TL}_{f(s+1)}$ is entered into $\mathrm{IS}_{f(s+1)}$, and the mean is obtained from the result of $\mathrm{IS}_{f s}$. When $\mathrm{IS}_{f s}$ is greater than the mean, $\left\{\mathrm{IS}_{33}, \mathrm{IS}_{43}, \mathrm{IS}_{53}, \mathrm{IS}_{63}, \mathrm{IS}_{72}, \mathrm{IS}_{82}\right\}$ is obtained. If IS $f_{s}$ cannot be optimized and $\mathrm{IS}_{f(s+1)}$ exceeds the mean, the decision suggestion plan can be obtained in Table 4 . That is, we have $\left\{\mathrm{IS}_{32}, \mathrm{IS}_{42}, \mathrm{IS}_{52}, \mathrm{IS}_{62}, \mathrm{IS}_{71}, \mathrm{IS}_{81}\right\}$.

With $f=2$ as the paradigm, $\mathrm{IS}_{62}=\mathrm{TL}_{61}-\mathrm{TL}_{62}$ and is consistently calculated as $\mathrm{IS}_{65}=\mathrm{TL}_{64}-\mathrm{TL}_{65}$. If $\mathrm{TL}_{f s}$ cannot be optimized, such as in $\mathrm{TL}_{61}$, the calculation is ignored. In this case, a differential mean of 0.17 was obtained and IS $_{63}$ was greater than the mean. However, $\mathrm{IS}_{62}$ cannot be optimized and $\mathrm{IS}_{63}$ is greater than the mean; thus, $\mathrm{IS}_{62}$ must also be considered.

We conduct intersection analysis from Tables 3 and 4 to obtain the scheduling solution. That is, we have $\left\{\mathrm{TL}_{17}, \mathrm{TL}_{18}, \mathrm{TL}_{26}, \mathrm{TL}_{27}, \mathrm{TL}_{28}, \mathrm{TL}_{35}, \mathrm{TL}_{36}\right\}$, where the values are organized from large to small, and the smaller number is subtracted from the larger number. The result of the subtraction is used to obtain the mean of 0.52 . The items larger than the mean are filtered out to obtain the results shown in Table 5, and the optimal decision suggestion is obtained as $\left\{\mathrm{TL}_{18}, \mathrm{TL}_{28}\right\}$.

The optimal solution displayed in Table 6 shows that, when the scheduling quantity is 45 reels, the trim loss ratio could be $3.3 \%$ or $1.2 \%$. Although the quantity of increased inventory differs, decision makers can select the desired inventory results according to their actual needs. The original scheduling quantity was 46 reels, and an optimal solution was not obtained. This means that, for $s=1$ or 2 cases with 45 or 46 reels, trim loss rate differences do not change significantly, and these two reels may be randomly selected. Thus, the scheduling quantity can be reduced to meet the actual requirements.

Concerning the unrestricted inventory quantity, such as $s=5$, this is a commonly obtained CSP result. Although the trim loss rate is $0.42 \%$, this optimal solution is occasionally unacceptable to the decision makers because it concentrates on the inventory production of 32 rolls of a specific paper width, such as $1000 \mathrm{~mm}$ (see Table 6). This poses significant challenges when considering how to reduce the paper width and quantity; this issue has consistently frustrated decision makers.

In the method ordinarily used in the paper industry, the first solution is typically aimed at implementing the order. The $\{1000,1100,1400\}$ inventory paper widths are not included. After optimization, the added paper widths with an inventory quantity of $\{1200,1900\}$ with $\{17,1\}$ are obtained. The total number of rolls is 134 , and the trim loss ratio is $5.2 \%$ (see Table 7). The postoptimization problems that occurred were as follows: (1) the rolls were not in multiples of 3; (2) the trim loss of $5.2 \%$ was excessive.

Therefore, manually disassembling the trim loss and the rolls with excessively varying patterns can be considered the optimal solution. The total numbers of rolls are confirmed as $135,138,141$, and so forth. In this case, the entire trim loss can only be reduced using 138 rolls or more. The rolls are adjusted manually to combine patterns $\{1,4\}$ with patterns $\{1,4\}$. To reduce the trim loss, the pattern $\{10\}$ configuration can be included in the inventory paper width, providing combinations of $\{1300,1400,1900\}$ or $\{1200,1500,1900\}$ or $\{1900,2500\}$ to obtain the combination $\{1000,1700,1900\}$. Finally, the order paper width $\{1800\}$ with pattern $\{1\}$ that cannot be allocated is combined with pattern $\{9\}$. A manual fine-tuning procedure is conducted to produce the scheduling quantity of 138 rolls and a trim loss ratio of $4.6 \%$ (see Table 8).

In Tables 6-8, we found that two solutions using the proposed method are obtained as follows: (1) the scheduling quantity is 45 reels with a trim loss ratio of $3.3 \%$; (2) the scheduling quantity is 45 reels with a trim loss ratio of $1.2 \%$. The solution using a traditional CSP is obtained as the scheduling quantity is 45 reels with a trim loss ratio of $0.42 \%$. The paper width with an inventory quantity of $\{1000,1100,1400\}$ with $\{32,4,3\}$ is obtained. However, this solution is unacceptable because these paper widths are not met for customers' requirements. We delete the $\{1000,1100,1400\}$ inventory paper width. After optimization, we obtain the added paper widths with an inventory quantity of $\{1200,1900\}$ with $\{17,1\}$, and the total number 
TABLE 6: Optimal solutions using our proposed method and the traditional method.

\begin{tabular}{|c|c|c|c|c|c|c|c|c|}
\hline \multirow{5}{*}{$\mathrm{PW}_{k}(\mathrm{~mm})$} & \multicolumn{8}{|c|}{$S$} \\
\hline & $1^{*}$ & 1 & $2^{*}$ & 2 & 2 & 3 & 3 & $5^{\#}$ \\
\hline & \multicolumn{8}{|c|}{ PSQ } \\
\hline & 45 & 46 & 45 & 46 & 47 & 47 & 48 & 45 \\
\hline & \multicolumn{8}{|c|}{$\mathrm{NPW}_{f_{s k}}$} \\
\hline 1000 & 5 & 5 & 10 & 10 & 10 & 15 & 15 & 32 \\
\hline 1100 & 5 & 5 & 10 & 10 & 10 & 15 & 15 & 4 \\
\hline 1200 & 5 & 5 & 10 & 10 & 10 & 15 & 15 & 13 \\
\hline 1300 & 5 & 5 & 10 & 10 & 10 & 9 & 11 & 0 \\
\hline 1400 & 5 & 5 & 4 & 9 & 9 & 0 & 1 & 3 \\
\hline 1500 & 4 & 4 & 0 & 2 & 2 & 0 & 0 & 0 \\
\hline 1600 & 0 & 0 & 0 & 0 & 0 & 1 & 0 & 0 \\
\hline 1700 & 0 & 0 & 0 & 0 & 0 & 0 & 0 & 0 \\
\hline 1800 & 0 & 0 & 0 & 0 & 0 & 0 & 0 & 0 \\
\hline 1900 & 0 & 0 & 0 & 0 & 0 & 0 & 0 & 0 \\
\hline 2000 & 0 & 0 & 0 & 0 & 0 & 0 & 0 & 0 \\
\hline 2100 & 0 & 0 & 0 & 0 & 0 & 0 & 0 & 0 \\
\hline 2200 & 0 & 0 & 0 & 0 & 0 & 0 & 0 & 0 \\
\hline 2300 & 0 & 0 & 0 & 0 & 0 & 0 & 0 & 0 \\
\hline 2400 & 0 & 2 & 0 & 0 & 0 & 9 & 14 & 0 \\
\hline 2500 & 1 & 5 & 0 & 2 & 8 & 0 & 0 & 0 \\
\hline Trim loss (\%) & 3.3 & 3.0 & 1.2 & 0.95 & 0.74 & 0.31 & 0.21 & 0.42 \\
\hline Trim loss (mm) & 20300 & 19300 & 7200 & 6000 & 4800 & 2000 & 1400 & 2600 \\
\hline
\end{tabular}

Note:" a traditional CSP solution; ${ }^{*}$ optimal CSP solution.

TABLE 7: The results of a traditional CSP method.

\begin{tabular}{|c|c|c|c|c|c|c|c|c|c|c|c|c|c|c|c|c|}
\hline \multirow{2}{*}{$\mathrm{PW}_{k}(\mathrm{~mm})$} & \multirow{2}{*}{ Order } & \multirow{2}{*}{ Optimal solution } & \multirow{2}{*}{ Inventory } & \multicolumn{13}{|c|}{ Pattern } \\
\hline & & & & 1 & 2 & 3 & 4 & 5 & 6 & 7 & 8 & 9 & 10 & 11 & 12 & 13 \\
\hline $1000^{*}$ & 0 & 0 & 0 & & & & & & & & & & & & & \\
\hline $1100^{*}$ & 0 & 0 & 0 & & & & & & & & & & & & & \\
\hline 1200 & 7 & 24 & 17 & 1 & 1 & & & & & & & & & & & \\
\hline 1300 & 22 & 22 & 0 & & & 1 & 1 & & & & & & & & & \\
\hline $1400^{*}$ & 0 & 0 & 0 & & & & & & & & & & & & & \\
\hline 1500 & 28 & 28 & 0 & & & & & 2 & & & & & & & & \\
\hline 1600 & 58 & 58 & 0 & 1 & & 2 & 1 & 1 & & & & & & & & \\
\hline 1700 & 47 & 47 & 0 & & 2 & & 1 & & & & & & & & & \\
\hline 1800 & 43 & 43 & 0 & 1 & & & & & 1 & 1 & 1 & 1 & & & & \\
\hline 1900 & 7 & 8 & 1 & & & & & & & & & & 2 & & & \\
\hline 2000 & 20 & 20 & 0 & & & & & & & & & & & 2 & & \\
\hline 2100 & 9 & 9 & 0 & & & & & & 1 & & & & & & & \\
\hline 2200 & 30 & 30 & 0 & & & & & & & & & & & & 2 & \\
\hline 2300 & 7 & 7 & 0 & & & & & & & 1 & & & & & & 2 \\
\hline 2400 & 12 & 12 & 0 & & & & & & & & 1 & & & & & \\
\hline 2500 & 20 & 20 & 0 & & & & & & & & & 1 & & & & \\
\hline & & Usage & & 1 & 23 & 21 & 1 & 14 & 9 & 1 & 12 & 20 & 4 & 10 & 15 & 3 \\
\hline & & tern trim loss & & 0 & 0 & 100 & 0 & 0 & 700 & 500 & 400 & 300 & 800 & 600 & 200 & 0 \\
\hline
\end{tabular}

Note: total rolls used $=134$; percent waste $=5.2 \% ;{ }^{*}$ nonorder product. 
TABLE 8: The results of a manual fine-tuning procedure.

\begin{tabular}{|c|c|c|c|c|c|c|c|c|c|c|c|c|c|c|c|c|}
\hline \multirow{2}{*}{$\mathrm{PW}_{k}(\mathrm{~mm})$} & \multirow{2}{*}{ Order } & \multirow{2}{*}{ Adjusted quantity } & \multirow{2}{*}{ Inventory } & \multicolumn{13}{|c|}{ Pattern } \\
\hline & & & & 1 & 2 & 3 & 4 & 5 & 6 & 7 & 8 & 9 & 10 & 11 & 12 & 13 \\
\hline $1000^{*}$ & 0 & 7 & 7 & & & & & & & & & & 1 & & & \\
\hline $1100^{*}$ & 0 & 0 & 0 & & & & & & & & & & & & & \\
\hline 1200 & 7 & 23 & 16 & 1 & 1 & & & & & & & & & & & \\
\hline 1300 & 22 & 23 & 1 & & & 1 & 1 & & & & & & & & & \\
\hline $1400^{*}$ & 0 & 0 & 0 & & & & & & & & & & & & & \\
\hline 1500 & 28 & 28 & 0 & & & & & 2 & & & & & & & & \\
\hline 1600 & 58 & 58 & 0 & 1 & & 2 & 1 & 1 & & & & & & & & \\
\hline 1700 & 47 & 55 & 8 & & 2 & & 1 & & & & & & 1 & & & \\
\hline 1800 & 43 & 43 & 0 & 1 & & & & & 1 & 1 & 1 & 1 & & & & \\
\hline 1900 & 7 & 7 & 0 & & & & & & & & & & 1 & & & \\
\hline 2000 & 20 & 20 & 0 & & & & & & & & & & & 2 & & \\
\hline 2100 & 9 & 9 & 0 & & & & & & 1 & & & & & & & \\
\hline 2200 & 30 & 30 & 0 & & & & & & & & & & & & 2 & \\
\hline 2300 & 7 & 7 & 0 & & & & & & & 1 & & & & & & 2 \\
\hline 2400 & 12 & 12 & 0 & & & & & & & & 1 & & & & & \\
\hline 2500 & 20 & 21 & 1 & & & & & & & & & 1 & & & & \\
\hline & & Usage & & 0 & 23 & 21 & 2 & 14 & 9 & 1 & 12 & 21 & 7 & 10 & 15 & 3 \\
\hline & & tern trim loss & & 0 & 0 & 100 & 0 & 0 & 700 & 500 & 400 & 300 & 0 & 600 & 200 & 0 \\
\hline
\end{tabular}

Note: total rolls used $=138$; percent waste $=4.6 \%$; ${ }^{*}$ nonorder product.

of rolls is 134 with a trim loss ratio of $5.2 \%$. Unfortunately, the number of rolls $(=134)$ is not in multiples of 3 . Thus, this solution is still unacceptable. The solution of the scheduling quantity using the manual method is obtained as 46 reels with a trim loss ratio of $4.6 \%$. We found that the scheduling quantity of our method is 45 reels that it is less than 46 reels obtained using the manual method. In addition, the trim loss using our method is lower than that of the manual method. Thus, we conclude that our method outperforms the other two methods.

\section{Conclusions}

In this study, we propose a new decision model for the CSP to improve the overall production efficiency in the paper industry. Not only using the mutual collocation of scheduling volume adjustment, orders, and inventory reduces the ratio of depletion to total production amount, but also the model for adjusting the scheduling amount proposed in this study obtains the data differentiation of the depletion ratio. This information can enable decision makers to solve the inventory and depletion problems related to CSP issues efficiently. In illustrative example, we found that the scheduling quantity of our method is 45 reels that it is less than 46 reels obtained using the manual method. That is, the cost effect of the number of reels can be reduced by 1 . Furthermore, it allows decision makers to determine the optimal configurations and controls for scheduling, orders, inventory, and trim loss.

In this study, we do not include the due date for the order. Future research should address this issue. In addition, we will conduct the flexible inventory allocation and trim loss control to determine the production scheduling quantity in the paper industry.

\section{Conflict of Interests}

The authors declare that there is no conflict of interests regarding the publication of this paper.

\section{Acknowledgments}

The authors gratefully acknowledge three reviewers of this paper who helped clarify and improve this presentation.

\section{References}

[1] P. C. Gilmore and R. E. Gomory, "A linear programming approach to the cutting-stock problem," Operations Research, vol. 9, no. 6, pp. 849-859, 1961.

[2] W. Gochet and M. Vandebroek, "A dynamic programming based heuristic for industrial buying of cardboard," European Journal of Operational Research, vol. 38, no. 1, pp. 104-112, 1989.

[3] C. H. Dağli, "Knowledge-based systems for cutting stock problems," European Journal of Operational Research, vol. 44, no. 2, pp. 160-166, 1990.

[4] H. Foerster and G. Wäscher, "Simulated annealing for order spread minimization in sequencing cutting patterns," European Journal of Operational Research, vol. 110, no. 2, pp. 272-281, 1998.

[5] P. H. Vance, "Branch-and-price algorithms for the onedimensional cutting stock problem," Computational Optimization and Applications, vol. 9, no. 3, pp. 211-228, 1998.

[6] M. Gradišar, G. Resinovič, J. Jesenko, and M. Kljajić, "A sequential heuristic procedure for one-dimensional cutting," European Journal of Operational Research, vol. 114, no. 3, pp. 557-568, 1999. 
[7] M. Sakawa, "Interactive fuzzy programming for multi-level 0-1 programming problems through genetic algorithms," European Journal of Operational Research, vol. 114, no. 3, pp. 580-588, 1999.

[8] S. M. A. Suliman, "Pattern generating procedure for the cutting stock problem," International Journal of Production Economics, vol. 74, no. 1-3, pp. 293-301, 2001.

[9] W. Weng and T. Sung, "Optimization of a line-cutting procedure for ship hull construction by an effective tabu search," International Journal of Production Research, vol. 46, no. 21, pp. 59355949, 2007.

[10] J. A. Abbasi and M. H. Sahir, "Development of optimal cutting plan using linear programming tools and MATLAB algorithm," International Journal of Innovation, Management and Technology, vol. 1, pp. 483-492, 2010.

[11] G. C. Wang, C. P. Li, J. Lv, X. X. Zhao, and H. Y. Cuo, "An effect algorithm design for the one-dimensional cutting-stock problem," Advanced Materials Research, vol. 602-604, pp. 17531756, 2013.

[12] M. Ali, C. W. Ahn, and M. Pant, "Trim loss optimization by an improved differential evolution," Mathematical Problems in Engineering, vol. 2013, Article ID 706350, 8 pages, 2013.

[13] W. Tharmmaphornphilas, S. Puemsin, and P. Siripongwutikorn, "A MILP model to select cutting machines and cutting patterns to minimize paper loss," in Proceedings of the International MultiConference of Engineers and Computer Scientists, pp. 11551160, Hong Kong, March 2013.

[14] R. Morabito and M. Arenales, "Optimizing the cutting of stock plates in a furniture company," International Journal of Production Research, vol. 38, no. 12, pp. 2725-2742, 2000.

[15] S. Menon and L. Schrage, "Order allocation for stock cutting in the paper industry," Operations Research, vol. 50, no. 2, pp. 324332, 2002.

[16] G. Wäscher, H. Haußner, and H. Schumann, "An improved typology of cutting and packing problems," European Journal of Operational Research, vol. 183, no. 3, pp. 1109-1130, 2007.

[17] K. Matsumoto, S. Umetani, and H. Nagamochi, "On the onedimensional stock cutting problem in the paper tube industry," Journal of Scheduling, vol. 14, no. 3, pp. 281-290, 2011.

[18] A. Mobasher and A. Ekici, "Solution approaches for the cutting stock problem with setup cost," Computers \& Operations Research, vol. 40, no. 1, pp. 225-235, 2013.

[19] M. C. Gramani and P. M. França, "The combined cutting stock and lot-sizing problem in industrial processes," European Journal of Operational Research, vol. 174, no. 1, pp. 509-521, 2006.

[20] A. Ritvirool, "A trim-loss minimization in a produce-handling vehicle production plant," Journal of Science and Technology, vol. 29, no. 1, pp. 157-164, 2007.

[21] S. S. Chauhan, A. Martel, and S. D’Amour, "Roll assortment optimization in a paper mill: an integer programming approach," Computers and Operations Research, vol. 35, no. 2, pp. 614-627, 2008.

[22] S. C. Poltroniere, K. C. Poldi, F. M. B. Toledo, and M. N. Arenales, "A coupling cutting stock-lot sizing problem in the paper industry," Annals of Operations Research, vol. 157, no. 1, pp. 91-104, 2008.

[23] L. Kos and J. Duhovnik, "Cutting optimization with variablesized stock and inventory status data," International Journal of Production Research, vol. 40, no. 10, pp. 2289-2301, 2002.

[24] M. Gradišar, G. Resinovič, and M. Kljajić, "Evaluation of algorithms for one-dimensional cutting," Computers \& Operations Research, vol. 29, no. 9, pp. 1207-1220, 2002.
[25] P. Trkman and M. Gradišar, "One-dimensional cutting stock optimization in consecutive time periods," European Journal of Operational Research, vol. 179, no. 2, pp. 291-301, 2007.

[26] A. C. Cherri, M. N. Arenales, and H. H. Yanasse, "The onedimensional cutting stock problem with usable leftover-a heuristic approach," European Journal of Operational Research, vol. 196, no. 3, pp. 897-908, 2009.

[27] Y. Cui and Y. Yang, "A heuristic for the one-dimensional cutting stock problem with usable leftover," European Journal of Operational Research, vol. 204, no. 2, pp. 245-250, 2010.

[28] S. A. Araujo, A. A. Constantino, and K. C. Poldi, "An evolutionary algorithm for the one-dimensional cutting stock problem," International Transactions in Operational Research, vol. 18, no. 1, pp. 115-127, 2011.

[29] J. Erjavec, M. Gradišar, and P. Trkman, "Assessment of stock size to minimize cutting stock production costs," International Journal of Production Economics, vol. 135, no. 1, pp. 170-176, 2012.

[30] J. Erjavec, M. Gradišar, and P. Trkman, "Renovation of the cutting stock process," International Journal of Production Research, vol. 47, no. 14, pp. 3979-3996, 2009.

[31] P. Keskinocak, F. Wu, R. Goodwin et al., "Scheduling solutions for the paper industry," Operations Research, vol. 50, no. 2, pp. 249-259, 2002.

[32] “Lingo Software," Version 11, Lindo Systems, Chicago, Ill, USA, 2009. 


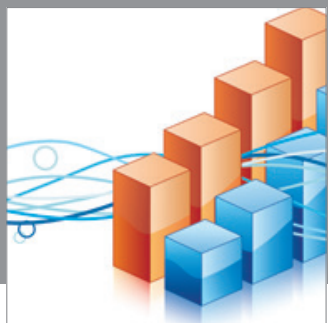

Advances in

Operations Research

mansans

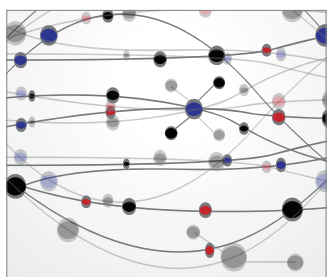

The Scientific World Journal
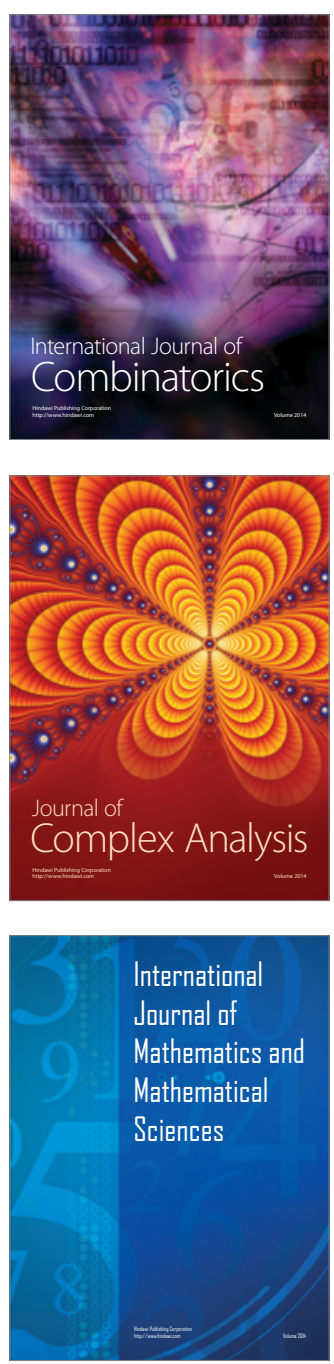
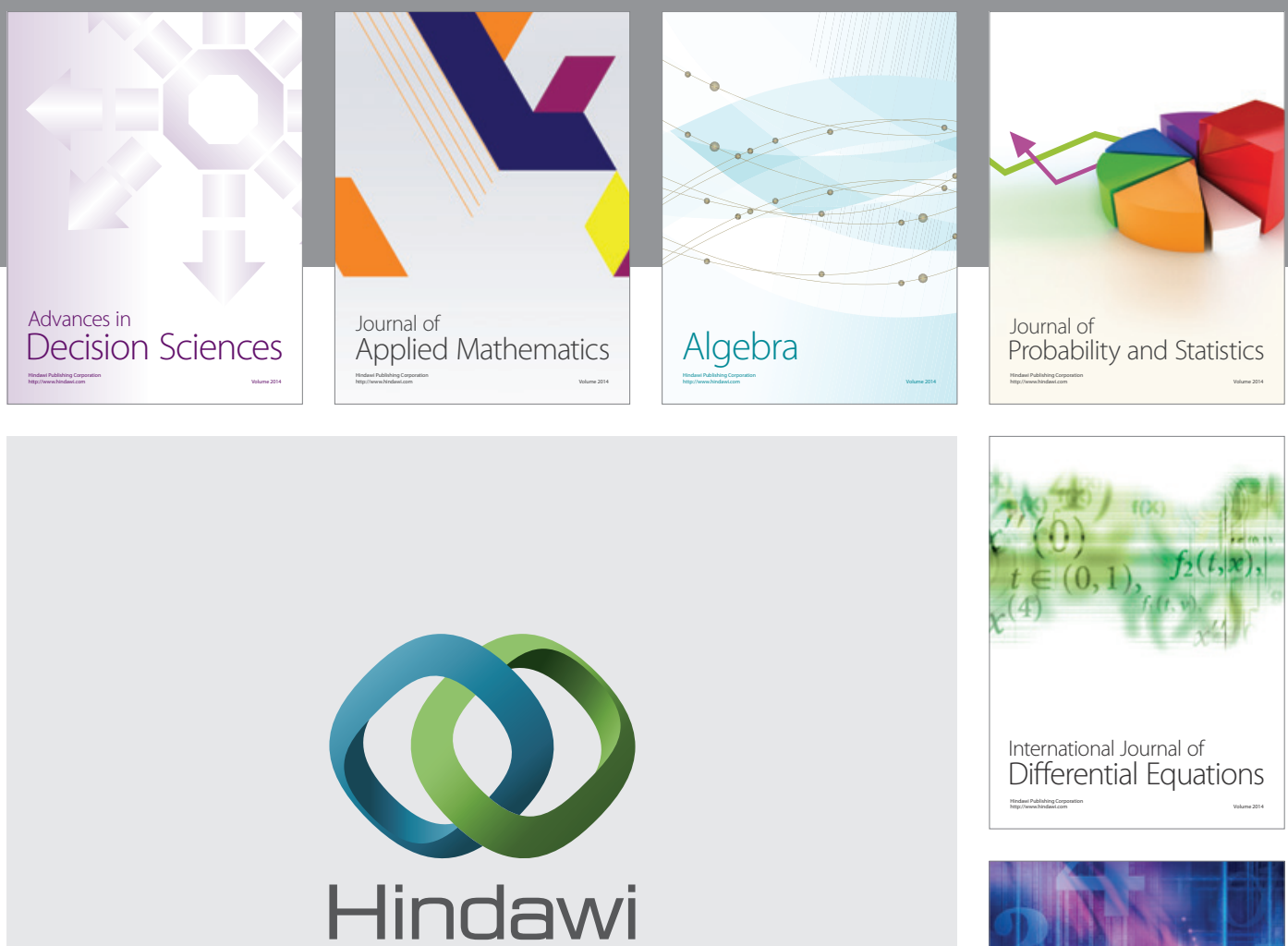

Submit your manuscripts at http://www.hindawi.com
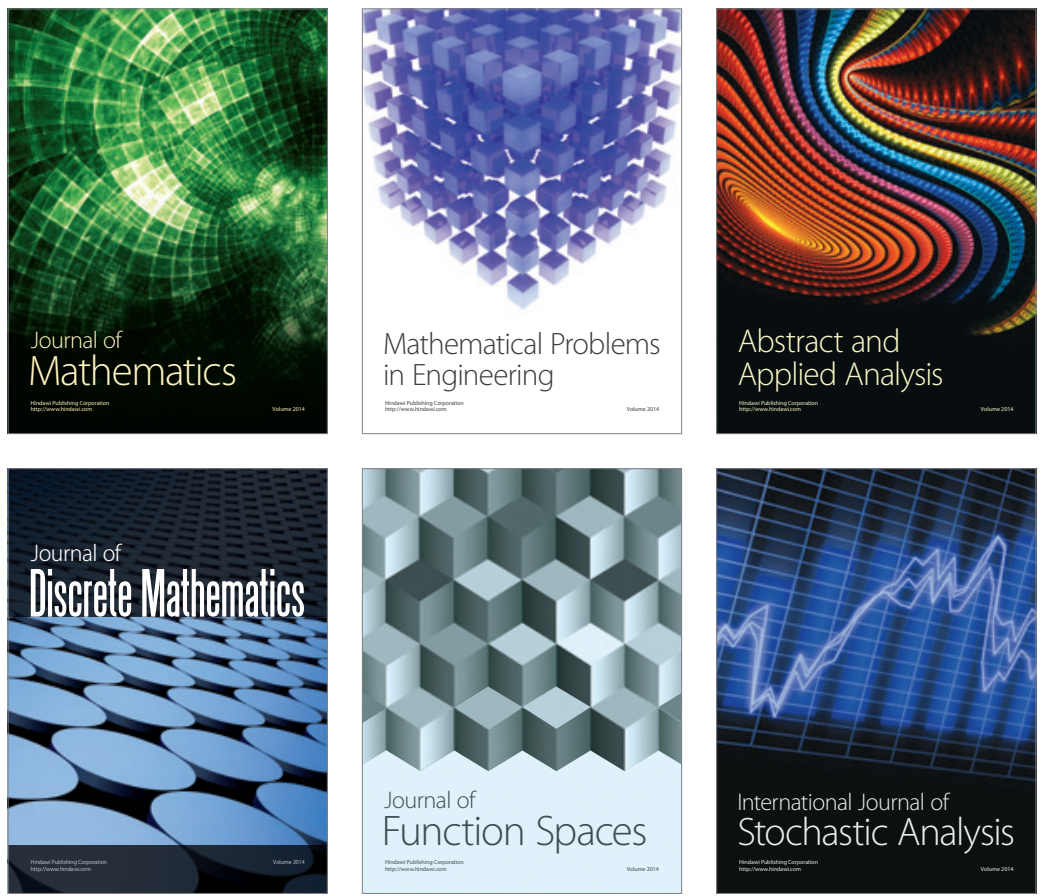

Journal of

Function Spaces

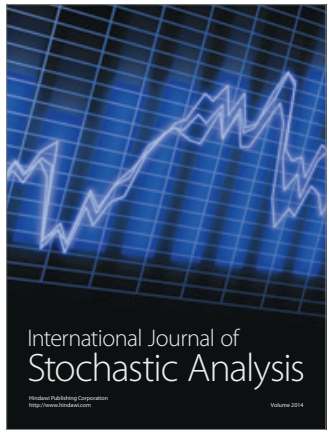

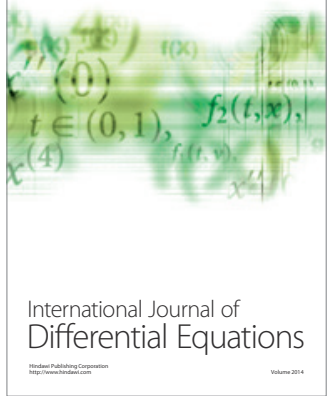
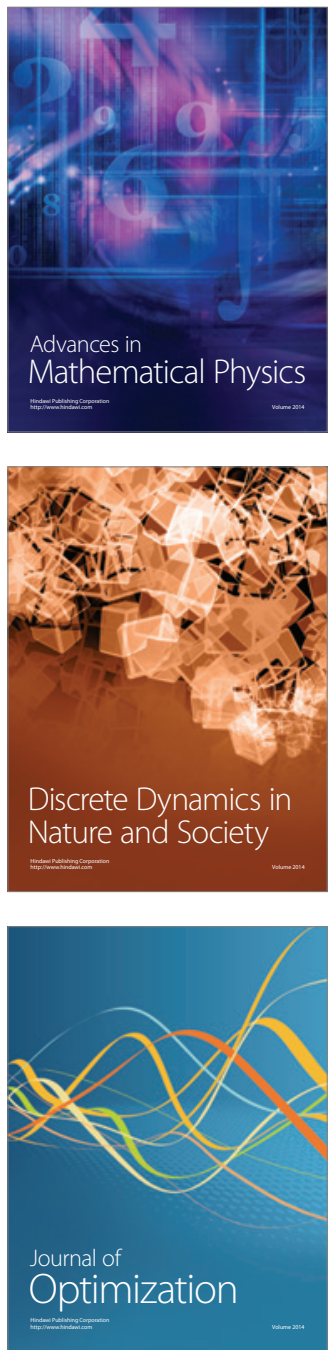